Artigos

Volume 8 - 2018|n. 4

\title{
A Política de Fundos (Fundef/Fundeb) e suas Disparidades no Financiamento da Educação Básica no Estado do Rio Grande do Sul
}

\author{
Nelton Carlos Conte \\ Universidade de Passo Fundo (UPF), Passo fundo/RS - Brasil
}

\section{Resumo}

O objetivo deste artigo foi analisar se os fundos contábeis, conforme se estruturam no Fundef e no Fundeb, diante da complexidade da estrutura federativa brasileira, têm se constituído em alternativa adequada para o financiamento da educação. Por meio de uma pesquisa descritiva e documental, com dados do período 2005 a 2014, foi analisado o impacto dos fundos nas finanças dos 497 municípios gaúchos, segregados em regiões dos Coredes/RS e em faixas populacionais. A pesquisa evidenciou que municípios que apresentam ganhos de recursos com o fundo são os mais populosos e com maior PIB (produto interno bruto), o que promove a concentração de recursos para o financiamento da educação em poucas regiões do estado do Rio Grande do Sul. As conclusões e apontamentos elencados procuram contribuir para o debate do novo modelo de financiamento da educação básica, uma vez que o Fundeb tem sua vigência até o ano de 2020.

Palavras-chave: Federalismo Fiscal. Financiamento da Educação. Fundef. Fundeb.

\section{The Funding Policy (Fundef / Fundeb) and its Disparities in the Funding of K-12 Education in the State of Rio Grande do Sul}

\begin{abstract}
The purpose of this article was to analyze whether the accounting funds, as structured in Fundef and Fundeb, in view of the complexity of the Brazilian federal structure, has been an appropriate alternative for the financing of education. By means of a descriptive and documentary research, with data from 2005 to 2014, the impact of the funds on the finances of the 497 municipalities of Rio Grande do Sul state, segregated in Coredes/RS regions and in population groups, was analyzed. The research evidenced that municipalities that present resources gain with the Fund are those with the largest population and with the highest GDP, which promotes the concentration of resources for the financing of education in a few regions of the state. The conclusions and notes of this study are intended to contribute to the debate about the new model of funding for $\mathrm{K}-12$ education, considering that Fundeb will be valid until 2020.
\end{abstract}

Keywords: Fiscal Federalism. Education Funding. Fundef. Fundeb. 
A Política de Fundos (Fundef/Fundeb) e suas Disparidades no Financiamento da Educação Básica no Estado do Rio Grande do Sul

\section{Introdução}

A organização federativa e a repartição de competências entre os níveis de governo têm expressão específica no setor educacional. O estudo das políticas educacionais no Brasil não pode ser adequadamente compreendido sem a discussão das instituições que historicamente regularam as relações intergovernamentais em educação básica no país. Como destaca Couto (2006), estudar as políticas educacionais a partir da metade da década de 1990 significa estudar os processos de redistribuição das responsabilidades das esferas de poder no que concerne à oferta dos serviços educacionais. Significa analisar as formas como estão sendo operacionalizadas as garantias de oportunidade de oferta para todos e, além disso, significa atentar para as tendências do poder público, no sentido de cumprir os direitos de cidadania do homem brasileiro em relação à educação.

A ação do Estado no período de 1994 a 2007 foi marcada por reestruturação da gestão da política educacional, sobretudo no campo do ensino fundamental e, mais recentemente, na educação básica. É importante salientar que a ação do governo federal no período introduziu novos mecanismos de gestão, definiu critérios técnicos na determinação de recursos, motivados por uma racionalidade financeira, induziu a descentralização institucional e financeira das ações.

Ocorreram três novidades cruciais: a aprovação da Lei de Diretrizes e Bases da Educação (LDB, Lei Federal $n^{\circ}$ 9394/2006); a instituição do Fundo de Manutenção e Desenvolvimento do Ensino Fundamental e Valorização do Magistério (Fundef), de iniciativa do Ministério da Educação (MEC); e mais recentemente a criação do Fundo de Manutenção e Desenvolvimento da Educação Básica e de Valorização dos Profissionais da Educação (Fundeb), em substituição ao Fundef.

O financiamento de políticas públicas por meio da constituição de um fundo se realiza pela destinação de receitas específicas que, por lei, se vinculam à realização de determinados objetivos. O efeito equalizador deste mecanismo de financiamento se dá de duas formas: 1) pela redistribuição dos recursos do fundo em proporção à oferta de matrículas, corrigindo desigualdades intraestaduais, isto é, entre os valores disponíveis ao governo estadual e aos municípios de cada estado para o financiamento da educação básica; 2) pela participação da União no financiamento dos fundos, a fim de garantir a aplicação de um valor mínimo nacionalmente estabelecido e, para tanto, recursos federais são destinados para complementar os fundos estaduais nos quais este valor mínimo não é alcançado. Assim, o Fundef e, posteriormente o Fundeb, foi apresentado como um exemplo inovador de política social que tinha entre os objetivos principais promover uma política nacional de equidade.

Em virtude das singularidades de cada rede de ensino, as formas de gerenciamento, a quantidade de recursos próprios e pelo tratamento dado aos seus profissionais da educação, a equidade torna-se um conceito vago e subjetivo. Por isso, nesta análise, em relação à equidade, detivemo-nos em verificar o que poderia ser mensurável por meio dos recursos disponíveis para as redes municipais.

O estudo parte do pressuposto de que o fundo, ao estabelecer um valor per capita aluno único no âmbito de cada UF sem considerar o padrão, a estrutura de demanda local, considerada elemento fundamental na provisão de serviços municipais, promoveu concentração de recursos para o financiamento da educação básica em municípios e regiões 
A Política de Fundos (Fundef/Fundeb) e suas Disparidades no Financiamento da Educação Básica no Estado do Rio Grande do Sul

com melhor infraestrutura e melhores indicadores econômicos. Nessa direção, este trabalho teve como objetivo analisar se os fundos contábeis, conforme se estruturam no Fundef e no Fundeb, diante da complexidade da estrutura federativa brasileira, têm se constituído em alternativa adequada para promover uma maior equidade na provisão e no financiamento da educação básica nos municípios gaúchos.

Trata-se de uma pesquisa quantitativa desenvolvida por meio de procedimentos metodológicos que envolvem a revisão bibliográfica e documental, sendo estudado o período de 2005 a 2014 (dois últimos anos do Fundef e oito anos do Fundeb). Foi analisada a participação do governo estadual e dos municípios na composição e nos repasses provenientes dos fundos, bem como o saldo obtido por cada nível de governo com as informações desagregadas por municípios, conforme faixas populacionais, e a partir do recorte territorial regional estabelecido pelos Coredes ${ }^{1}$ do estado do Rio Grande do Sul.

\section{Análise Federativa Territorial dos Efeitos Distributivos da Política de Fundos Contábeis (Fundef e Fundeb) no Financiamento da Educação Básica no Estado do Rio Grande do Sul}

A avaliação das políticas públicas é importante para o planejamento das ações do governo e para o controle da sociedade no uso dos recursos públicos. Concordamos com a proposição de Verhine (2003, p. 41) de que "[...] analisar o impacto de uma determinada política pública ou programa social é buscar discuti-la em seus múltiplos aspectos, procurando avaliar o grau de alcance dos objetivos e metas propostos".

Iniciamos a avaliação do impacto distributivo da política de fundos contábeis por uma análise federativa vertical intrarredes, verificando a participação de cada esfera (estado e municípios) na distribuição dos recursos do fundo e a sua respectiva participação no número de matrículas.

O Fundef e o Fundeb, como mencionado, adotaram como mecanismo de distribuição dos recursos do fundo o número de matrículas. No ano de 2006, último ano do Fundef, o conjunto dos municípios recebeu $48,3 \%$ dos recursos distribuídos pelo fundo, sendo que sua participação nas matrículas era de $48,4 \%$, ou seja, mantinha-se uma equivalência entre a distribuição de recursos e proporção nas matrículas. Com a introdução do Fundeb, passa a ocorrer um leve distanciamento das variáveis participações nas receitas e nas matrículas. No ano de 2009 , com o fundo na sua totalidade implementado a participação dos municípios nos recursos do fundo era de $43,8 \%$ e nas matrículas de $44,9 \%$, ou seja, uma diferença de $1,1 \%$.

O distanciamento das variáveis participação nas receitas e número de matrículas nos primeiros anos do Fundeb é melhor compreendido quando avaliado o comportamento do

\footnotetext{
A proposta é analisar o Rio Grande do Sul através dos seus Conselhos Regionais de Desenvolvimento (Coredes). Estes foram implantados no Rio Grande do Sul no ano de 1991 e sancionados pela Lei Estadual $n^{\circ}$ 10.283 em 1994. Os Coredes servem para promover uma maior e melhor integração entre as regiões do Estado, procurando promover discussões e decisões sobre políticas e ações a serem implantadas, visando promover o desenvolvimento socioeconômico entre os municípios. Os Conselhos Regionais de Desenvolvimento têm por objetivo "[...] a promoção do desenvolvimento regional, harmônico e sustentável, através da integração dos recursos e das ações do governo na região, propondo à melhoria da qualidade de vida da população, à distribuição quantitativa da riqueza produzida, ao estímulo à permanecia do homem em sua região e à preservação e recuperação do meio ambientell (Art. $2^{\circ}$ da Lei 10 283). Atualmente, o Estado apresenta 28 COREDES, com um total de 497 municípios.
} 
A Política de Fundos (Fundef/Fundeb) e suas Disparidades no Financiamento da Educação Básica no Estado do Rio Grande do Sul

número de matrículas na rede pública de ensino no estado do Rio Grande do Sul, que forma o critério de distribuição do fundo. Com a entrada em vigor do Fundeb, já em seu primeiro ano, o número de matriculas base para distribuição dos recursos cresceu $16,6 \%$, passando para 1.964.829 matrículas. No ano de 2009, quando da vigência plena do fundo, o número de matrículas cresceu $43,4 \%$ quando comparado ao último ano de vigência do Fundef. O maior crescimento ocorre na rede estadual, que amplia o número de matrículas em $53,4 \%$, enquanto que nos municípios o crescimento é de $32,8 \%$. No ano de 2014 , a participação dos municípios nas receitas se eleva para $48,6 \%$, sendo que a participação nas matrículas é de $49,3 \%$. No mesmo ano, as receitas do Fundeb totalizaram $\mathrm{R} \$ 7,2$ bilhões, sendo que a diferença percentual entre a participação nas receitas distribuídas pelo fundo e a participação das matrículas é de $0,7 \%$, o que representa uma perda de $\mathrm{R} \$ 50,5$ milhões para os municípios. $O$ Gráfico 1 sintetiza esse comportamento.

\section{Gráfico 1 - Participação do Estado e dos Municípios do Rio Grande do Sul no Número de} Matrículas e no Retorno do Fundeb no Ano de 2014

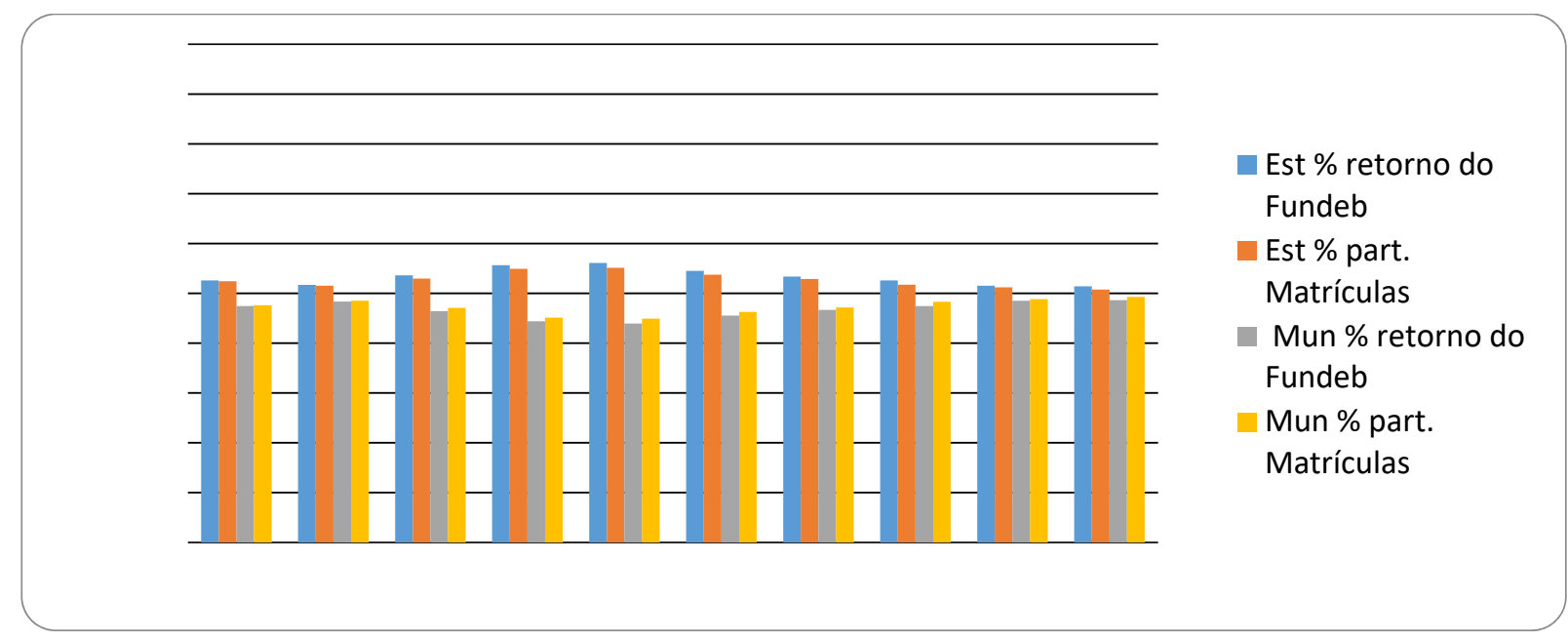

Fonte: Elaborada pelo autor - base de dados FNDE.

Com o Gráfico 1 percebemos que os municípios vêm aumentando sua participação no número de matrículas nos últimos períodos de análise, o que ocorre preferencialmente nos níveis do ensino infantil e fundamental. No ensino fundamental, no ano de 2005, os municípios detinham $48,5 \%$ das matrículas. No ano de 2014 , essa participação cresce para $54,3 \%$. Já no ensino infantil, no ano de 2005, mesmo não computando para base do Fundef, os municípios detinham 73,2\% das matrículas. A participação aumenta para $96,1 \%$ no ano de 2014 .

Uma consequência do aumento da participação municipal nas matrículas da educação é a ruptura do equilíbrio entre alunos atendidos e capacidade financeira dos municípios. Assim, embora os municípios já possuam um número de matrícula na educação básica igual àquela apresentada pelos estados, sua receita líquida de impostos é bem inferior àquela obtida pelos estados (cerca de três quartos), o que demonstra uma situação de grande fragilidade do atual sistema de financiamento (PINTO, 2007).

Na mesma linha, Gil (2006) entende que a política de fundos na educação não passou de uma competente estratégia para transferir aos municípios responsabilidades que até então eram da União e dos estados e manter, ao custo mais baixo que for tolerável, para as crianças pobres - e só para elas - uma escola pobre. "O velho lema que os cínicos (pré/pós) liberais pregavam em políticas públicas: 'aos pobres, a pobreza' vê-se consolidado através do Fundef. 
A Política de Fundos (Fundef/Fundeb) e suas Disparidades no Financiamento da Educação Básica no Estado do Rio Grande do Sul

Nunca o Governo Federal gastou, de forma tão competente, tão pouco no ensino fundamental" (ARELARO; GIL, 2006, p. 83).

Já a diferença observada na participação nas receitas e nas matrículas ocorre porque, na distribuição dos recursos do Fundeb, além do critério número de matrículas é adicionado o critério do valor do custo-aluno-ano (fator de ponderação). A fixação dos fatores de ponderação parte do fator base $=1,0$ (atribuído ao segmento séries iniciais do ensino fundamental urbano), de forma que, para os demais segmentos, a fixação dos fatores deve observar o espaço de variação entre 0,7 (menor fator) e 1,30 (maior fator), conforme art. 10, $\S \S 1^{\circ}$ e $2^{\circ}$, da Lei $n^{\circ} 11.494$ (BRASIL, 2007). Com esse critério, a aplicação desses fatores de ponderação resultará em valores por aluno/ano específicos para cada segmento da educação básica, de tal sorte que o menor valor corresponderá a $70 \%$ do valor base e o maior valor por aluno/ano será $30 \%$ superior ao valor base.

Esta diferenciação traz vantagem para o estado, que concentra quase a totalidade dos alunos do ensino médio público e traz desvantagens para os municípios, que concentram a maioria dos alunos da creche e da pré-escola, segmentos da educação básica que têm custo mais elevado para sua execução que os do ensino fundamental e médio (CASTRO, 2011; CRUZ 2011). Nesse aspecto, como salienta Bremamaeker (2011), o Fundeb foi desfavorável para os municípios, que antes recebiam recursos estaduais para manutenção do ensino fundamental e que passaram a repartir recursos com o financiamento do ensino médio.

A Comissão Intergovernamental de Financiamento para a Educação Básica de Qualidade - MEC vem ajustando os fatores de ponderação aplicáveis entre as diferentes etapas da educação básica, sendo a última alteração para vigência no exercício de 2016. 0 ajuste foi publicado no Diário Oficial da União (DOU), por meio da Resolução $n^{\circ} 1$, de 29 de julho de 2015 (FNDE, 2015). Os ajustes promovidos reduzem a distância entre os níveis de ensino creche e pré-escola, de competência constitucional dos municípios, e do ensino médio, de competência estadual, mas ainda não eliminam a distância favorável ao estado no fator de ponderação. Quando comparado o valor de contribuição para fundo e o respectivo retorno financeiro, a vantagem inverte-se em favor dos municípios. No ano de 2006 , o conjunto dos municípios contribui para o fundo com $\mathrm{R} \$ 788,3$ milhões, obtendo um retorno de $\mathrm{R} \$ 1,1$ bilhão, ou seja, um ganho de $\mathrm{R} \$ 322$ milhões de reais.

Essa sistemática não se modificou com o Fundeb. Em 2009, os municípios contribuíram com $\mathrm{R} \$ 1,6$ bilhões para o fundo e tiveram um retorno de $\mathrm{R} \$ 1,9$ bilhões, ou seja, ganho de $\mathrm{R} \$ 309,5$ milhões. Em 2014, a contribuição foi de $\mathrm{R} \$ 2,6$ bilhões, e o retorno, de 3,5 bilhões, um ganho de $\mathrm{R} \$ 908,7$ milhões. O Gráfico 2 mostra a formação da receita do Fundef/Fundeb com os valores que a rede municipal contribuiu e recebeu de retorno na redistribuição intrarredes no ano de 2014. 
A Política de Fundos (Fundef/Fundeb) e suas Disparidades no Financiamento da Educação Básica no Estado do Rio Grande do Sul

\section{Gráfico 2 - Composição do Financiamento ao Fundeb no Ano de 2014 pelas Redes Municipais de Ensino do Estado do Rio Grande do Sul no Ano de 2014}

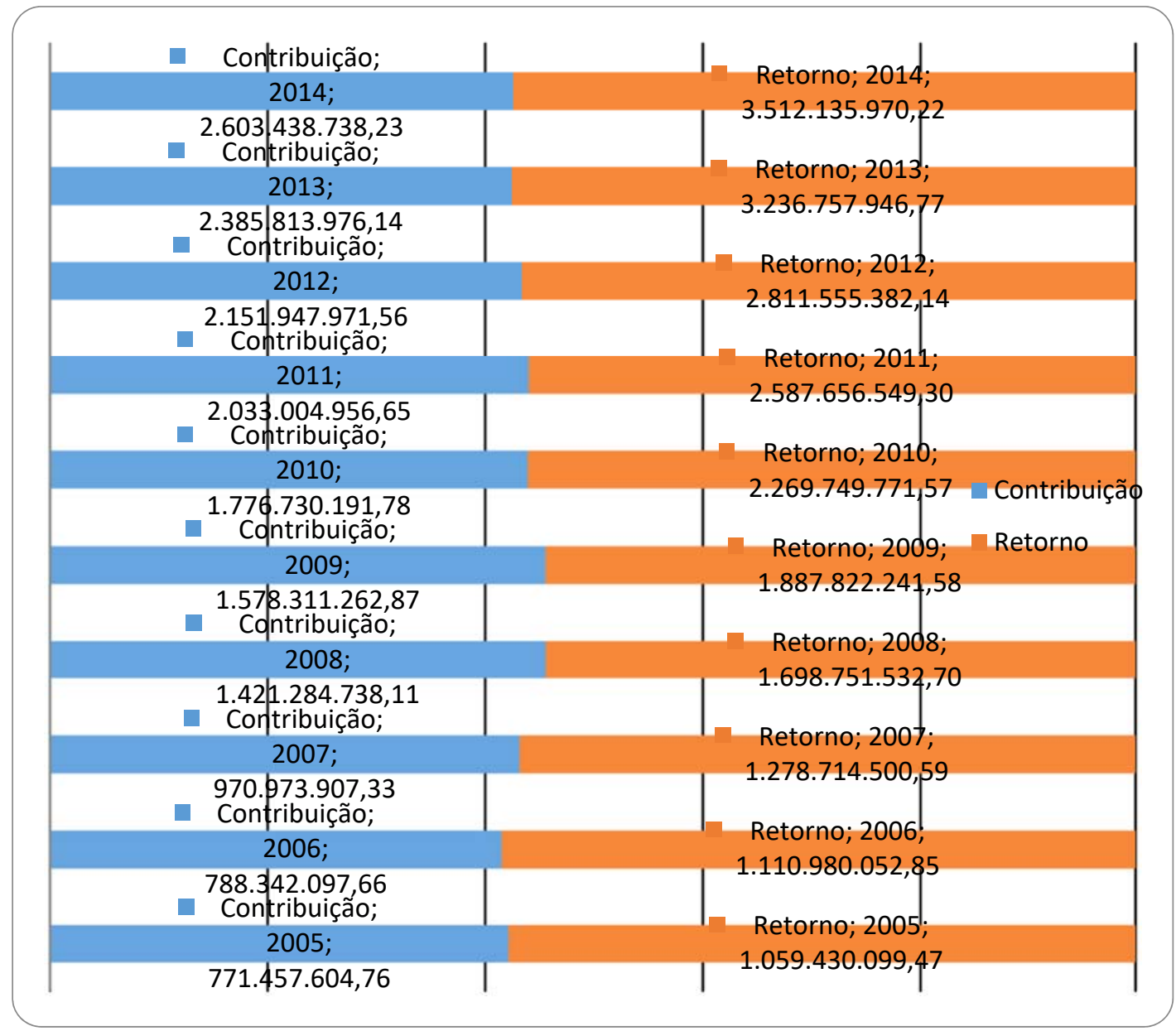

Fonte: Elaborado pelo autor.

Esses números mostram, inicialmente, que os municípios aumentaram substancialmente suas receitas com os fundos em detrimento da rede estadual de ensino. No entanto, uma análise dos valores redistribuídos intrarredes revela que, em 2006, o percentual de redistribuição da rede estadual de ensino entre as redes municipais era de 14,1\%. Já em 2009 , com o Fundeb, o percentual de redistribuição reduz para 7,2\%. Enquanto que, em 2014, apesar do crescimento, representou $12,5 \%$ do montante das receitas do fundo, ou seja, ainda inferior aos do patamar de 2006 com o Fundef.

O valor redistribuído pelo Fundef, e posteriormente com o Fundeb, do estado em favor dos municípios não significa que todos os municípios tenham ganhado recursos com os fundos. Uma análise federativa horizontal mostra que, no ano de 2006, dos 496 municípios do estado, 330 apresentaram perda de recursos com o fundo, o que representa $66,5 \%$ dos municípios; 196 tiveram ganho, o que equivale a 33,5\% dos municípios, ou seja, 1/3 dos municípios do estado concentraram os ganhos de recursos do fundo oriundos das perdas do estado e das perdas dos demais municípios. O saldo entre ganhos e perdas com o fundo apresentava uma média de $-1,68 \%$ da receita disponível dos municípios, com uma mediana de $-2,09 \%$ e um desvio padrão de $6,24 \%$, o que mostra que o ganho com o Fundef registrado pelos municípios, em detrimento do governo estadual, não ocorre de forma homogênea entre 
A Política de Fundos (Fundef/Fundeb) e suas Disparidades no Financiamento da Educação Básica no Estado do Rio Grande do Sul

os municípios. Em 2014, último ano de análise deste estudo, a perda média entre os municípios é de $-1,68 \%$, com perda máxima de $-16,32 \%$ e o maior ganho de $21,34 \%$. Dos 497 municípios do estado, 299 apresentaram perda de recursos com o fundo, equivalente $60,2 \%$, e 198 obtiveram ganho, o que representa $39,8 \%$.

Para uma análise temporal do ganho/perda dos municípios com o Fundef e Fundeb elaboramos um indicador de desempenho com o fundo, sendo atribuído 1 ponto para cada exercício contábil (ano civil) em que o município obteve ganho com o fundo e 0 pontos quando teve perda de recursos. Como o período de análise deste estudo é de 10 anos, 2005 a 2014, cada município poderia obter uma pontuação máxima de 10 pontos e mínima de 0 ponto.

Dos 497 municípios do estado, 237 obtiveram pontuação zerada, o que equivale a $47,7 \%$ dos municípios, ou seja, apresentaram perdas com o Fundef e Fundeb em todos os exercícios contábeis. Se considerarmos os municípios que obtiveram pontuação 4 ou inferior, este número sobe para 303 municípios, o que equivale a $61 \%$ dos municípios do estado. $\mathrm{A}$ localização dos municípios com respectiva pontuação é mostrada no Mapa 1.

Mapa 1 - Localização dos Municípios do Estado do Rio Grande do Sul com a Pontuação Obtida no Indicador de Ganho e Perdas com Fundef e Fundeb no Período de 2005 a 2014

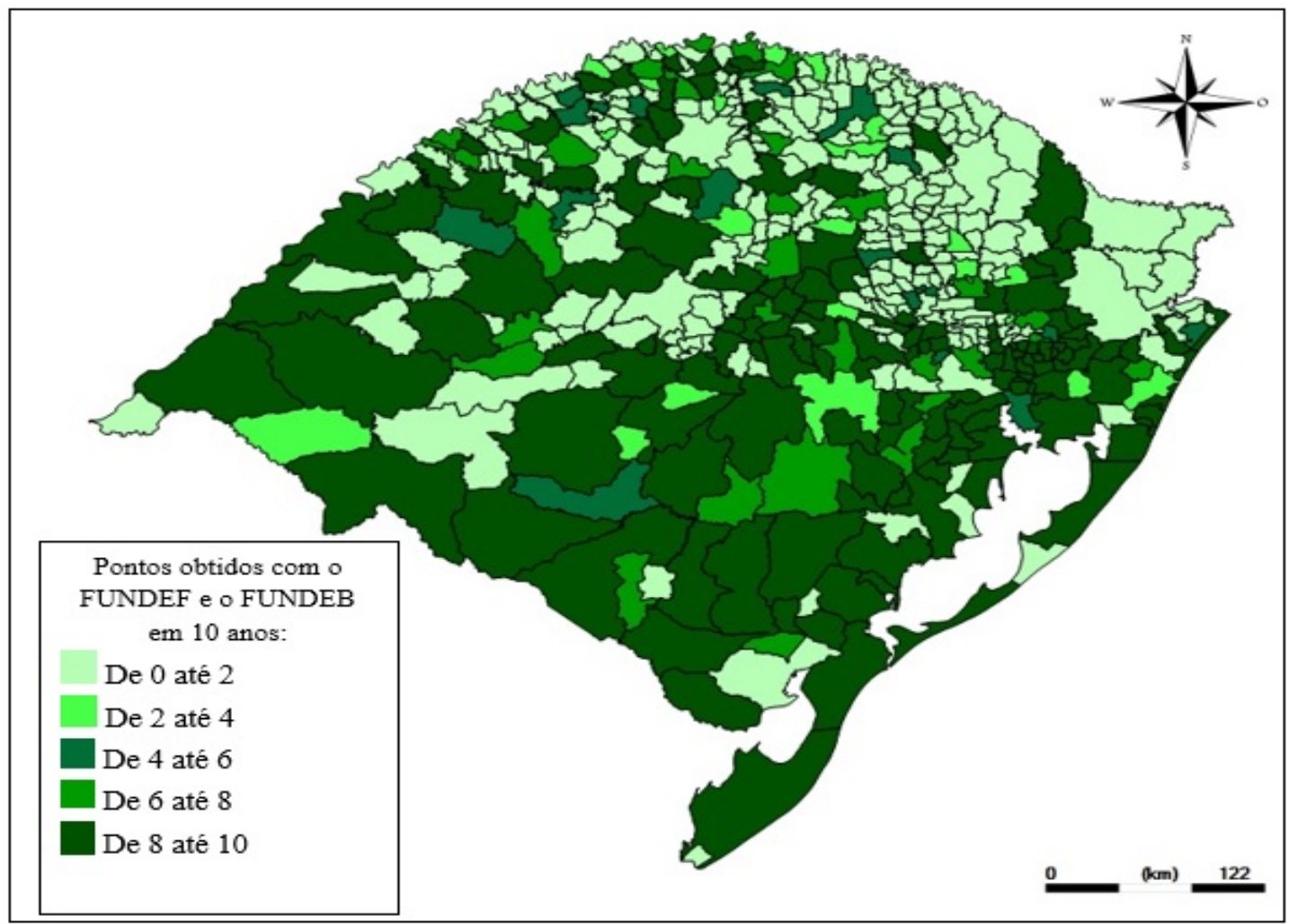

Fonte: Elaborado pelo autor com o Software IpeaGEO versão 2.1.15_06_26.

O mapa mostra que a maioria dos municípios que apresenta perdas com os fundos mantém essa condição em todos os períodos da série. O mesmo ocorre com os municípios que são ganhadores de recurso, o que mostra a existência de uma situação ótimo de Pareto ${ }^{2}$ dos fundos de financiamento da educação.

2 O ótimo de Pareto, ou Paretto efficiency, é utilizado em estudos econômicos para avaliar a eficiência de determinada alocação de recursos, é o marco para medir resultados. Reflete a posição na qual, para fazer uma 
Os números confirmam as críticas ao Fundeb defendidas por Castro (2011), Bremaeker (2011) e Cruz (2009) de que o fundo não conseguiu promover uma equidade de recursos, por promover a redistribuição de recursos no âmbito de cada estado e pela reduzida complementação do governo federal - no caso do Estado do Rio Grande do Sul não ocorreu aporte do governo federal.

Quando analisada a perda e o ganho de recursos com o Fundeb por regiões dos Coredes, utilizando o mesmo indicador adotado para os municípios, 10 regiões apresentaram pontuação superior a $50 \%$, ou seja, o conjunto de municípios apresentou ganho de recursos, e 18 regiões tiveram pontuação inferior a $50 \%$, indicando perda de recursos. A região que obteve maior pontuação é a região do Corede Vale do Rio dos Sinos, atingindo $100 \%$ dos pontos possíveis. Também se destacam as regiões dos Coredes Paranhana Encosta da Serra, com pontuação de $83 \%$, e a Metropolitana Delta do Jacuí, com pontuação de $80 \%$.

Entre as regiões com menor pontuação, as regiões norte e nordeste são as que apresentam pior desempenho, com 5\% e 7,9\%. Também apresentam pontuações reduzidas as regiões Rio da Varzea e Produção, com 12\% e 12,8\%, respectivamente. O Mapa 2 apresenta a localização dos Coredes que apresentaram ganho e dos que apresentaram perda de recursos com o Fundef e o Fundeb no período de 2005-2014.

\section{Mapa 2 - Localização dos Coredes com Resultado no Indicador de Perdas e Ganhos com o Fundef e Fundeb, Período 2005-2014}

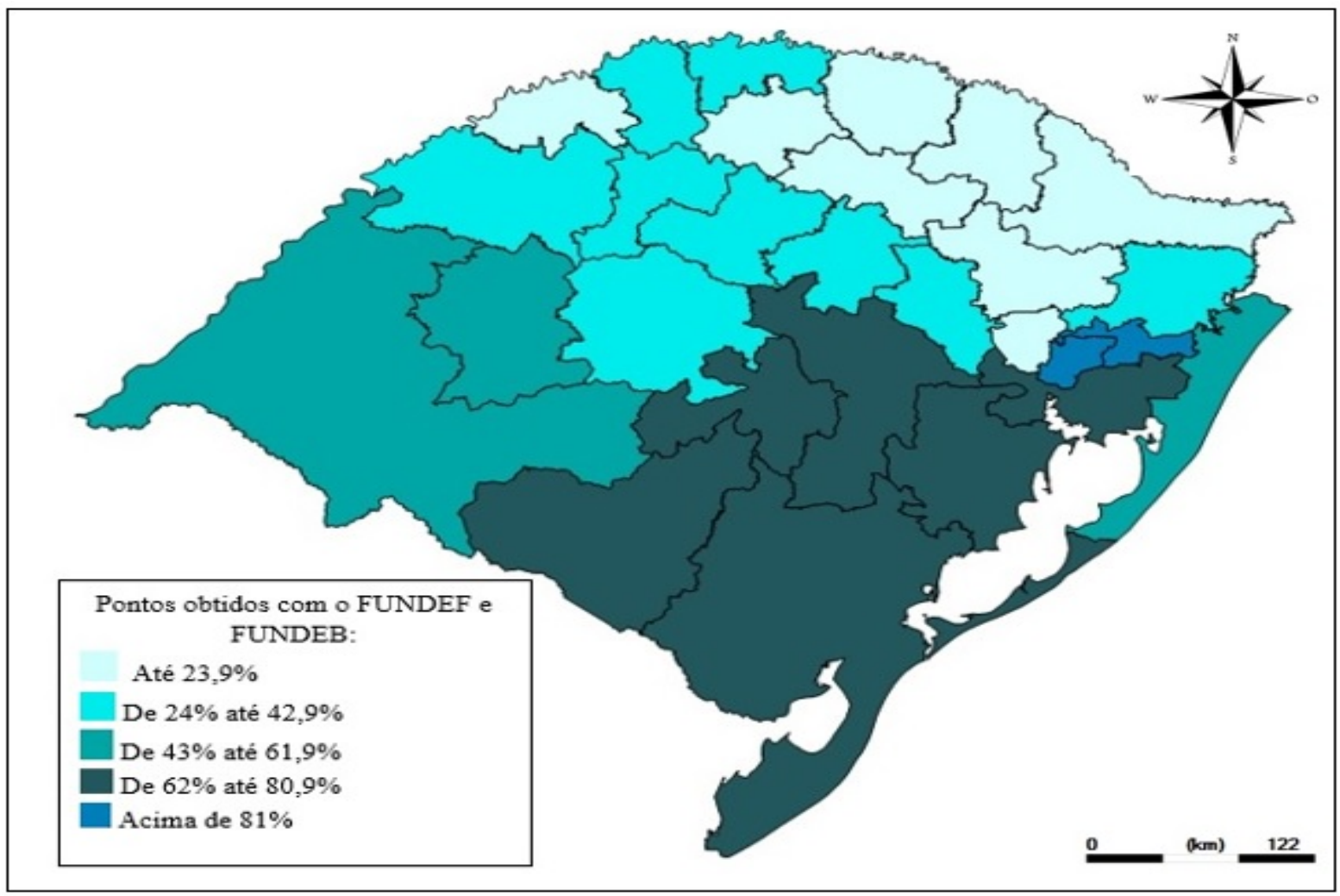

Fonte: Elaborado pelo autor com o Software IpeaGEO versão 2.1.15_06_26.

pessoa melhorar a sua situação, necessariamente alguém será prejudicado ou terá a sua satisfação reduzida. Ou seja, em uma distribuição que não seja ótima é possível incrementar a satisfação de alguém sem reduzir a de outra pessoa. 
A Política de Fundos (Fundef/Fundeb) e suas Disparidades no Financiamento da Educação Básica no Estado do Rio Grande do Sul

Os resultados, de forma análoga, convergem com o que defendem Mendes, Miranda e Cosio (2008), que a distribuição regional, em nível de país, dos recursos da educação tem sido, na prática, menos distributiva que aquela associada aos demais fundos (FPM e FPE), a despeito de sua intenção equalizadora. Ressaltam os autores que esse caráter menos redistributivo associado aos gastos com educação tende a agravar o problema regional, já que na economia moderna a educação tem sido reconhecida como mola mestra do desenvolvimento.

Se as regiões mais desenvolvidas recebem proporções maiores dos gastos com educação, isso pode significar a ausência de um mecanismo de convergência econômica entre as regiões brasileiras e, [...] esse padrão também se repete quando as distribuições per capita são consideradas. (MENDES; MIRANDA; COSIO, 2008, p. 80).

A distribuição de recursos do fundo de financiamento da educação adota como critério único o número de matrículas, o que inverte parcialmente o efeito redistributivo promovido pelas transferências de FPM e da parcela do ICMS com características distributivas, que utilizam critérios diferentes de distribuição, como: inverso da população e renda no caso do primeiro; e área do município, produtividade primária e número de propriedades rurais no caso do segundo. Por sua vez, o número de matrículas tem relação direta com o fator demográfico. Os municípios e regiões com maior população, que são os mais industrializados e que apresentam as maiores receitas, é que tendem a apresentar ganhos com o fundo.

Esse processo converge com o que Myrdal (1965) denominou de causalidade cumulativa ou circular. Devido a essa causalidade circular, um processo social tende a se tornar cumulativo e frequentemente adquire velocidade em taxa acelerada. Esse princípio afirma que as disparidades regionais são guiadas por um efeito bola de neve, que resulta num reforço contínuo, uma vez iniciado.

A base teórica econômica regional (KRUGMAN, 1991; FUJITA; KRUGMAN; VENABLES, 2002) analisa a concentração espacial por meio dos fatores ou forças centrípetas e centrífugas de concentração e desconcentração das atividades econômicas, respectivamente atuando na configuração e na organização social diferenciada no território. Essa abordagem procura explicar os processos de concentração espacial por meio de um modelo de retornos crescentes, baseado na concepção centro-periferia. Explicam Campolina Diniz e Crocco (2006), que tomando duas regiões, uma desenvolvida e outra atrasada, as forças centrípetas fazem com que o processo de concentração seja cumulativo e esse processo só cessa diante do surgimento de forças centrífugas que o bloqueiem, permitindo o crescimento de regiões periféricas. O financiamento da educação poderia agir como essa força centrífuga.

A despeito de seu caráter contraditório enquanto política equitativa e de favorecer a desigualdade intrarregional, como explica Mendes (2012), é economicamente racional que as escolhas e as ações privadas e públicas se concentrem naquelas localidades ou regiões onde já existem grandes aglomerações de pessoas, de atividades produtivas, de infraestrutura, etc. $\mathrm{Na}$ realidade, porém, como o próprio Mendes (2012) ressalta, essa escolha racional não apenas econômica, mas também social ou política apenas reforça os ciclos viciosos praticados historicamente no país, reforçando e sedimentando cada vez mais os graves desequilíbrios na ação pública e as graves desigualdades regionais no país. De acordo com o mesmo autor, se o que se quer é exatamente conter a superconcentração em poucos 
A Política de Fundos (Fundef/Fundeb) e suas Disparidades no Financiamento da Educação Básica no Estado do Rio Grande do Sul

centros urbanos, que promove a grave concentração (social e regional) da produção e da renda, o Estado, em especial, deveria atuar de outra forma, anticíclica, em uma direção de conter a concentração.

O problema estaria, então, não numa irracionalidade na forma de como se distribui os recursos e os gastos púbicos, já que este se sustenta em um padrão racional de uma lógica econômica, mas na forma como o sistema federativo não dá conta de, dada essa lógica, conferir mecanismos (anticíclicos) de coordenação e/ou cooperação federativa que favoreçam a desconcentração, especialmente dos gastos públicos, compatibilizando-os com as demandas sociais específicas e, consequentemente, com as possibilidades mais efetivas de redução das desigualdades territoriais ou regionais.

\section{A Política de Fundos Contábeis (Fundef e Fundeb) e as Finanças dos Municípios do Estado do Rio Grande do Sul: balanço e impacto no período de 2005 a 2014}

Entendemos que é a capacidade de receita per capita aluno e o número de alunos por rede que vai determinar a condição de financiamento de cada rede de ensino e que a composição das receitas dos municípios, formadas pelas receitas próprias e pelas transferências intergovernamentais, determinam quanto cada município irá dispor de recursos. Na sequência buscou-se analisar a receita per capita aluno dos municípios do Estado do Rio Grande do Sul.

Como o objetivo do estudo é avaliar o impacto dos fundos contábeis de financiamento da educação nas receitas, foram projetados três cenários: o primeiro sem a existência dos fundos, mas mantendo-se a vinculação de receitas de no mínimo de $25 \%$ para MDE, como determina o artigo 212 da Constituição Federal (BRASIL, 1988); o segundo conforme regras e metodologia do Fundef; e o terceiro, com as regras em vigor do Fundeb. Os resultados são demonstrados no Gráfico 3. Em um primeiro cenário, projetado para o ano de 2014, sem a presença dos fundos contábeis de financiamento (Fundef e Fundeb), mantendo-se a vinculação mínima constitucional de $25 \%$ das receitas para a MDE, a receita/aluno/ano dos municípios com população inferior a 3.000 habitantes seria de $R \$ 12.479,83$, com um comportamento decrescente conforme o aumento da faixa populacional dos municípios; sendo que, para os municípios na faixa de população superior a 156.216 habitantes, a receita per capita aluno/ano seria de $\mathrm{R} \$ 4.898,29$, uma diferença de $155 \%$.

O comportamento da receita/aluno/ano nesse cenário sugere a presença de falta de escala e de aglomeração adequada para execução da despesa pública e na provisão eficiente de bens e serviços públicos locais. As receitas dos pequenos municípios (abaixo de 3.000 habitantes) são superiores, porque a despesa média é alta. É relativamente mais caro prover os mesmos bens públicos em locais com pouca infraestrutura, para poucas pessoas, o que eleva o custo fixo para a implantação de condições efetivas dessa provisão, compatibilizando com os resultados das pesquisas que apuraram o custo/aluno/ano.

Em um segundo cenário, com o Fundef, a receita per capita aluno nos municípios com população inferior a 3.000 habitantes seria de $\mathrm{R} \$ 8.295,84$ por aluno/ano, apresentando uma queda de $34 \%$ em comparação ao cenário anterior. Já a receita por aluno dos municípios com população superior a 156.216 habitantes cresceria $21,8 \%$ em relação ao cenário 1 , passando 
A Política de Fundos (Fundef/Fundeb) e suas Disparidades no Financiamento da Educação Básica no Estado do Rio Grande do Sul

para $\mathrm{R} \$ 5.967,57$. A diferença de receita per capita aluno entre os municípios de menor e maior população, que era de $155 \%$, reduz para $39 \%$.

Com as regras do Fundeb, sendo a política em vigor para o financiamento da educação básica até o ano de 2020, a diferença de receita per capita por aluno entre as faixas de população praticamente desaparecem. A diferença entre a receita dos municípios com população inferior a 3.000 habitantes e a dos com população superior a 156.516 habitantes é de $9,1 \%$ e, quando sem a existência dos fundos, esta era de $154,8 \%$. Nos municípios com população de até 3.000 habitantes, o valor per capita aluno em 2014 é de $\mathrm{R} \$ 6.901,18$, uma queda de $80,1 \%$ em relação ao cenário 1 ; já a dos municípios com população superior a 156.516 habitantes passa a ser de $\mathrm{R} \$ 6.323,99$, um ganho de $29,1 \%$ na mesma comparação.

Gráfico 3 - Comparação do Valor per Capita Aluno da Rede Municipal em Valores de 2014: MDE x Fundef x Fundeb, por Faixa de Proporção

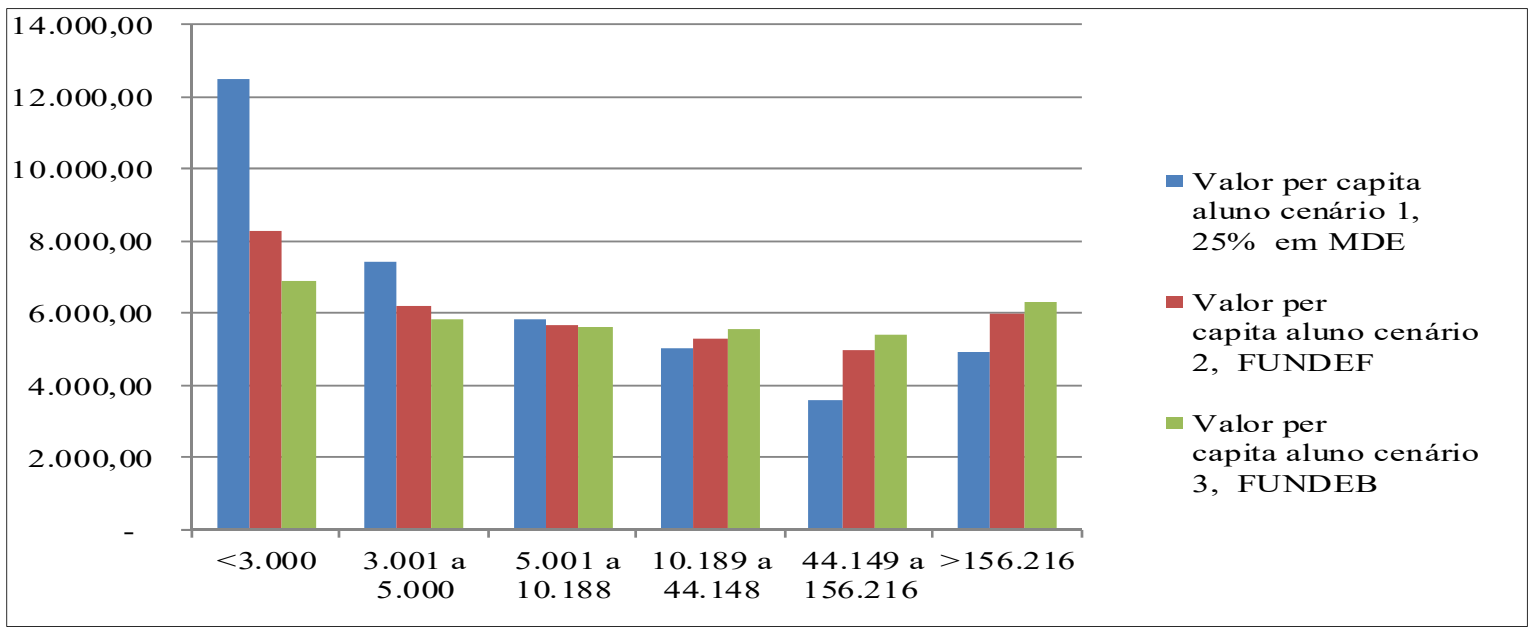

Fonte: Elaborado pelo autor.

Do ponto de vista regional, os padrões gerais da receita per capita aluno apresentam comportamentos diferentes quando comparado o financiamento com e sem a presença dos fundos contábeis de financiamento da educação básica para o ano de 2014. Sem a presença dos fundos, cenário 1 , mantendo-se a vinculação constitucional de $25 \%$ das receitas em educação, a maior receita per capita aluno seria da região Corede Fronteira Noroeste com valor de $\mathrm{R} \$ 8.900,46$ ano, seguida das regiões Corede Nordeste e Corede Norte com R\$ $8.191,36$ e $\mathrm{R} \$ 8.077,58$. Já as menores receitas per capita aluno seriam das Regiões Paranhana-Encosta da Serra, com R\$2.562,90, e nas Regiões Vale do Rio dos Sinos e Campanha, com valores de $\mathrm{R} \$ 3.352,76$ e $\mathrm{R} \$ 3.600,32$.

A nova política de financiamento da educação promovida pelo Fundef e atualmente pelo Fundeb traz alterações significativas no valor per capita aluno por região, como mostra o gráfico 11. Com o Fundeb, a maior receita per capita aluno ano passa a ser do Corede Metropolitana Delta do Jacuí com valor de $\mathrm{R} \$ 7.740,14$, um crescimento de $11,3 \%$ quando comparado ao cenário 1. As regiões que apresentavam os menores valores por aluno no cenário 1, como os casos do Corede Rio dos Sinos e Corede Paranhana-Encosta da Serra, são as que apresentaram o maior crescimento, de $47 \%$ e $65,5 \%$, respectivamente.

Em caminho contrário, a Região do Corede Fronteira Noroeste, que possuía o maior valor por aluno tem uma redução de $18,2 \%$ na receita per capita aluno, reduzindo o valor para 
$\mathrm{R} \$ 7.276,29$. A queda também é expressiva nos Coredes Nordeste, Norte e Rio da Varzea, com redução de $17,3 \%, 14,6 \%$ e $12,2 \%$.

Gráfico 4 - Comparação do Valor per Capita Aluno de Rede Municipal em Valores de 2014: MDE x Fundef x Fundeb, por Coredes

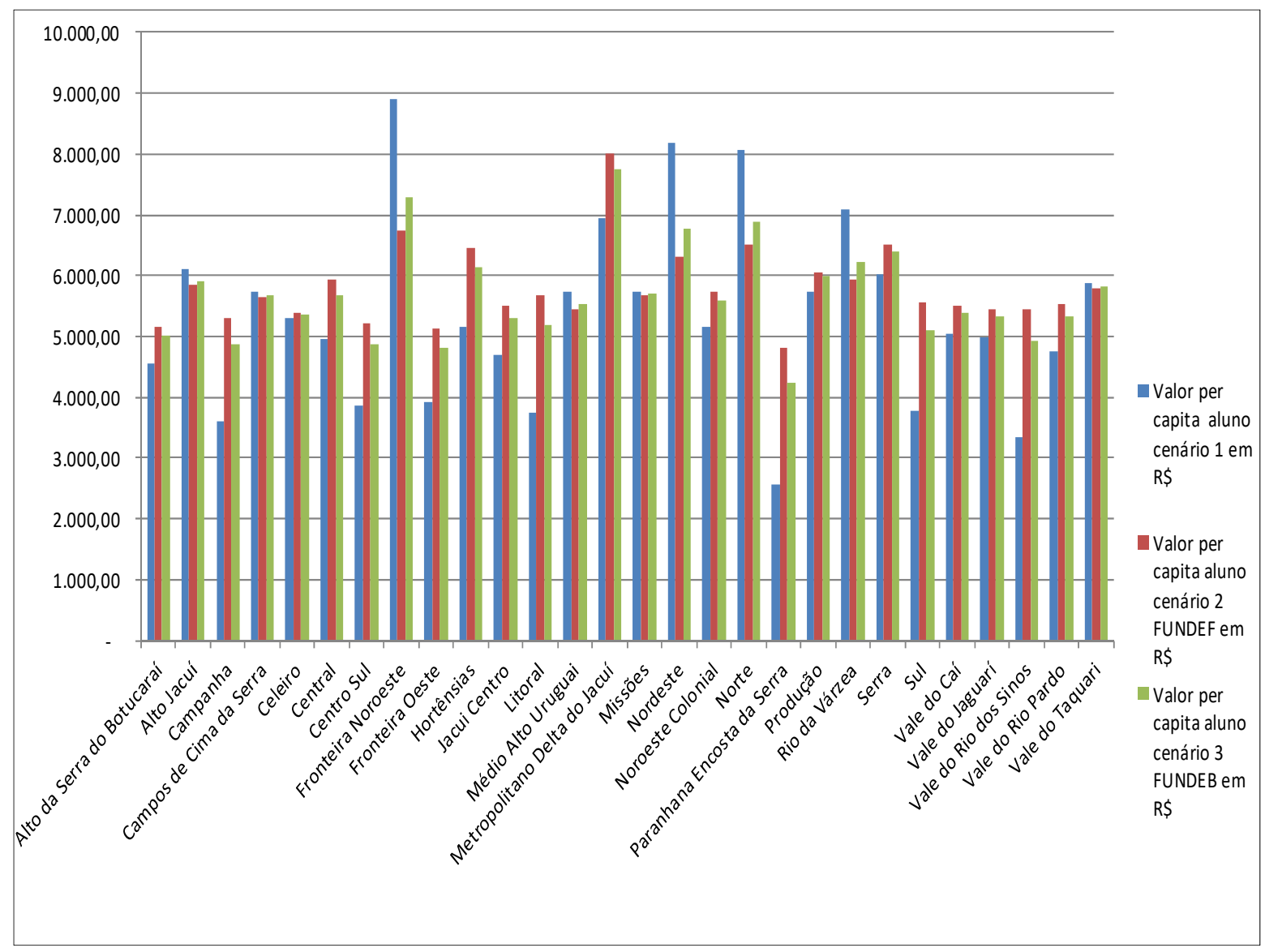

Fonte: Elaborado pelo autor.

Em síntese, para os municípios com maior população e regiões que concentram municípios com esse perfil demográfico, os impactos do Fundef e posteriormente do Fundeb são positivos, uma vez que as três faixas de população apresentam ganho de recursos com os fundos, como mostra a Tabela 1.

Tabela 1 - Ganhos e Perdas com o Fundef/Fundeb no Período de 2005-2014 nos Municípios do Estado do Rio Grande do Sul por Faixa de População em R\$1,00

\begin{tabular}{c|r|r|r|r|r}
\hline $\begin{array}{l}\text { Municípios por faixa } \\
\text { de população }\end{array}$ & \multicolumn{1}{|c|}{2006} & \multicolumn{1}{c|}{2007} & \multicolumn{1}{c}{2009} & \multicolumn{1}{c}{2011} & \multicolumn{1}{c}{2014} \\
\hline até 3.000 & $-46.585 .488,88$ & $-60.122 .214,75$ & $-88.392 .748,75$ & $-110.072 .774,92$ & $-134.870 .278,71$ \\
\hline de 3.001 a 5.000 & $-23.049 .536,45$ & $-31.903 .514,01$ & $-44.026 .613,81$ & $-54.331 .016,39$ & $-69.627 .380,70$ \\
\hline de 5.001 a 10.188 & $-16.369 .835,33$ & $-14.025 .768,92$ & $-14.388 .273,01$ & $-21.149 .737,09$ & $-25.879 .835,22$ \\
\hline de 10.189 a 44.148 & $50.933 .689,18$ & $48.227 .803,30$ & $84.354 .501,63$ & $173.191 .368,99$ & $248.475 .416,77$ \\
\hline de 44.149 a 156.216 & $126.649 .577,70$ & $134.727 .153,35$ & $205.523 .448,01$ & $334.560 .925,46$ & $423.249 .263,59$ \\
\hline acima de 156.216 & $190.683 .136,82$ & $195.263 .360,25$ & $210.871 .506,02$ & $343.963 .364,38$ & $479.748 .047,29$ \\
\hline
\end{tabular}

Fonte: Elaborada pelos autores. 
A Política de Fundos (Fundef/Fundeb) e suas Disparidades no Financiamento da Educação Básica no Estado do Rio Grande do Sul

Nos municípios com população de até 10 mil habitantes (331 municípios estão nesta faixa populacional no ano de 2014 , representando $66,7 \%$ do total de municípios do estado), as perdas no ano de 2014 foram de R $\$ 225,6$ milhões. No período de 2005 a 2014 totalizariam, em valores de 2014, R $\$ 2,35$ bilhões. Em caminho oposto, nos municípios com população superior a 156.216 habitantes (são 11 municípios, equivalendo a 2,4\% do total), os ganhos com o Fundef em 2014 totalizavam R $\$ 479,8$ milhões, equivalentes a 6,7\% dos recursos do fundo. Os ganhos com o Fundeb nos 10 anos da série analisada representam, em valores de 2014, R\$ 3,6 bilhões.

Os valores de perdas e ganhos com o Fundef e o Fundeb afetam a análise do cumprimento pelos municípios ao artigo 212 da Constituição Federal (BRASIL, 1988), o qual estabelece a obrigatoriedade de aplicação de no mínimo $25 \%$ das receitas com impostos e transferências na Manutenção e Desenvolvimento do Ensino - MDE. O impacto ocorre uma vez que as perdas com o fundo, mesmo não tendo sido aplicadas efetivamente na educação, são computadas contabilmente como valores aplicados na MDE, já os ganhos ocorridos com o fundo, mesmo sendo recursos financeiros recebidos e aplicados na MDE, não são considerados no cômputo do percentual. Assim, as análises dos valores aplicados com educação que não considerarem estas especificidades terão seus resultados prejudicados.

A Tabela 2 mostra quanto, para cada $\mathrm{R} \$ 1,00$ considerado contabilmente como gasto na Manutenção e Desenvolvimento do Ensino, foi efetivamente aplicado em educação pelos municípios do Estado do Rio Grande do Sul, nas diferentes faixas populacionais.

Tabela 2 - Perdas e Ganhos com o Fundef/Fundeb sobre o Investimento em MDE no período de 2005-2014

\begin{tabular}{l|r|r|r|r|r|r|r|r|r|r}
\hline $\begin{array}{l}\text { Municípios por faixa } \\
\text { de população }\end{array}$ & \multicolumn{1}{|c|}{2005} & \multicolumn{1}{c|}{2006} & \multicolumn{1}{c|}{2007} & 2008 & 2009 & 2010 & 2011 & 2012 & 2013 & 2014 \\
\hline até 3.000 & 0,68 & 0,68 & 0,64 & 0,63 & 0,59 & 0,60 & 0,59 & 0,59 & 0,60 & 0,61 \\
\hline de 3.001 a 5.000 & 0,83 & 0,85 & 0,80 & 0,78 & 0,79 & 0,82 & 0,79 & 0,77 & 0,80 & 0,80 \\
\hline de 5.001 a 10.188 & 0,99 & 0,93 & 0,86 & 0,94 & 0,96 & 1,00 & 0,95 & 0,94 & 0,96 & 0,96 \\
\hline de 10.189 a 44.148 & 1,17 & 1,09 & 1,08 & 1,15 & 1,17 & 1,25 & 1,23 & 1,21 & 1,24 & 1,23 \\
\hline de 44.149 a 156.216 & 1,38 & 1,34 & 1,33 & 1,40 & 1,41 & 1,50 & 1,53 & 1,44 & 1,49 & 1,48 \\
\hline acima de 156.216 & 1,54 & 1,50 & 1,50 & 1,58 & 1,54 & 1,61 & 1,62 & 1,55 & 1,59 & 1,58 \\
\hline
\end{tabular}

No exercício de 2006, último ano da vigência do Fundef, nos municípios com população de até 3 mil habitantes, para cada $\mathrm{R} \$ 1,00$ contabilizado como gasto em educação, o valor efetivamente aplicado era de $\mathrm{R} \$ 0,68$, ou seja, uma perda de $32 \%$ ocasionada pelo fundo de financiamento. Já nos municípios com população acima de 156 mil habitantes, para cada $\mathrm{R} \$$ 1,00 contabilizado, foram aplicados $\mathrm{R} \$ 1,50$ - um ganho de $50 \%$ gerado pelo fundo.

A entrada em vigor do Fundeb acentuou estas diferenças, mantidas em todos os períodos da série analisada. No exercício 2014, nos municípios com população inferior a 3 mil habitantes, para $R \$ 1,00$ contabilizado como receita em MDE, foram aplicados $R \$ 0,61$, ou seja, uma perda de $39 \%$ gerada pelo fundo, uma redução de $10 \%$ nas receitas disponíveis para financiamento da educação básica quando comparado ao exercício 2006. Em caminho contrário, os municípios com população superior a 156 mil habitantes, apresentaram ganhos com o novo fundo de financiamento. Para caca $R \$ 1,00$ contabilizado como receita em MDE, efetivamente foram aportados $\mathrm{R} \$ 1,58 \mathrm{em}$ receitas na MDE, um ganho de $58 \%$ ocasionado 
A Política de Fundos (Fundef/Fundeb) e suas Disparidades no Financiamento da Educação Básica no Estado do Rio Grande do Sul

pelo Fundeb, e um crescimento no valor disponível de 5,3\%, quando comparado ao exercício 2006.

A redução dos valores disponíveis para aplicação na MDE determinada pelo Fundef, e posteriormente pelo Fundeb, nos municípios com população inferior a 10 mil habitantes, ocasionou ajustes financeiros necessários à manutenção dos serviços públicos em educação. O primeiro foi o direcionamento de recursos não vinculados (de outras áreas) para fazer frente aos gastos, o que tem elevado o percentual aplicado na manutenção e no desenvolvimento do ensino, como mostra a Tabela 3.

Tabela 3 - Percentuais em Manutenção do Ensino pelos Municípios do Estado do Rio Grande do Sul no Período de 2005-2014

\begin{tabular}{l|r|r|r|r|r|r|r|r|r|r}
\hline $\begin{array}{l}\text { Municípios por faixa } \\
\text { de população }\end{array}$ & \multicolumn{1}{|c|}{2005} & \multicolumn{1}{c|}{2006} & 2007 & 2008 & 2009 & 2010 & 2011 & 2012 & 2013 & 2014 \\
\hline até 3.000 & 26,9 & 27,7 & 28,0 & 28,2 & 29,7 & 28,3 & 28,0 & 28,9 & 28,7 & 29,3 \\
\hline de 3.001 a 5.000 & 27,3 & 28,4 & 28,4 & 28,3 & 29,6 & 28,0 & 27,9 & 29,3 & 28,9 & 29,3 \\
\hline de 5.001 a 10.188 & 27,1 & 28,3 & 28,2 & 27,6 & 28,6 & 27,3 & 27,5 & 29,0 & 28,3 & 28,9 \\
\hline de 10.189 a 44.148 & 27,8 & 29,7 & 29,2 & 27,3 & 28,2 & 27,1 & 27,1 & 29,5 & 28,2 & 28,6 \\
\hline de 44.149 a 156.216 & 27,8 & 29,7 & 29,2 & 27,3 & 28,2 & 27,1 & 27,1 & 29,5 & 28,2 & 28,6 \\
\hline acima de 156.216 & 27,4 & 28,5 & 28,3 & 25,9 & 27,7 & 26,4 & 26,8 & 27,7 & 27,1 & 27,1 \\
\hline
\end{tabular}

Fonte: Elaborado pelos autores.

Esses resultados apontam que os municípios que apresentaram perdas com o Fundef, e principalmente com o Fundeb, tiveram que ampliar os recursos para manutenção e desenvolvimento do ensino, transferindo recursos próprios para cobrir parte das perdas geradas pelos fundos. Já os municípios que apresentaram ganhos com o Fundeb reduziram os percentuais aplicados na MDE, o que resulta em maior volume de recursos livres disponíveis para aplicação em outras áreas.

\section{Considerações Finais}

Este estudo buscou acrescentar ao construto teórico-metodológico uma abordagem que associasse o efeito distributivo (transferência intergovernamental) promovido pelos fundos contábeis de financiamento da educação e o impacto nas finanças dos municípios gaúchos.

Esses fundos, ao alterar o mecanismo de financiamento da educação, alteraram a estrutura do sistema tributário. Isso, para muitos autores, gerou uma minirreforma tributária, na qual $20 \%$ do produto das receitas oriundas das transferências distributivas são destinados para formação do fundo, sendo que a distribuição dos recursos se dá com a adoção de um novo mecanismo, o do valor per capita aluno, favorecendo os municípios com maior população, sendo também os que concentram a maior arrecadação tributária.

Esta pesquisa inovou em relação às demais por ter abordado os impactos distributivos do Fundef e do Fundeb em uma escala estadual (estado do Rio Grande do Sul), analisando seus impactos intraestado. Esses resultados apresentam uma série de implicações sobre a política de financiamento da educação. As evidências empíricas aqui encontradas sugerem que a estrutura de financiamento da educação por meio dos fundos contábeis apresenta alguns problemas, que devem ser contemplados no debate sobre o novo modelo de 
A Política de Fundos (Fundef/Fundeb) e suas Disparidades no Financiamento da Educação Básica no Estado do Rio Grande do Sul

financiamento da educação básica, uma vez que o Fundeb encerra sua vigência no ano de 2020.

A tese que não se verifica no Rio Grande do Sul é a de que as transferências das receitas dos fundos contábeis de financiamento da educação para os municípios têm contribuído para redução das disparidades. A receita do fundo guarda relação direta com o tamanho do município e o seu produto interno bruto, sendo que os municípios e, consequentemente, regiões, que ganham recursos são os mais populosos e de melhores indicadores econômicos. Isso contribui para uma relação circular (ciclo vicioso) na ação pública, na qual o Estado está mais presente em poucos centros urbanos ou mesmo em algumas regiões. A ação estatal apenas reforça e reitera esta estrutura de desigualdade histórica. Os resultados corroboram a literatura que vem indicando que o Estado favorece e contribui para a continuidade das desigualdades regionais ou territoriais (sociais, econômicas, etc.), por meio da distribuição do gasto público (receita) e dos investimentos no país.

Em suma, recomenda-se que o novo projeto de Lei de financiamento da educação básica, uma vez que o Fundeb tem vigência até o ano de 2020, contemple critérios de distribuição que valorizem o território, a heterogeneidade dos municípios e regiões. Uma prática que vem se generalizando, adotada pelo FNDE, e pode servir de alternativa para a metodologia dos fundos contábeis, é a adoção de diferenciadores que estabelecem montantes per capitas mais elevados, de acordo com características específicas dos municípios (localização, nível de desenvolvimento e de pobreza, área rural, etc.) ou em segmentos sociais atendidos (quilombolas, indígenas, níveis de escolaridade e vulnerabilidade da população etc.). Também devem ser reavaliados os fatores de ponderação utilizados pelos fundos contábeis, é incoerente que o ensino médio tenha um fator de ponderação superior ao de creches e pré-escola, que apresentam um custo superior.

Ao longo deste estudo, foram feitos alguns recortes para torná-lo exequível. Entendese, porém, que pesquisas futuras poderão abordar especificamente alguns desses aspectos. O primeiro deles seria avaliar o aspecto distributivo intraestadual do Fundeb em outros estados brasileiros que apresentam características distintas do Estado do Rio Grande do Sul, como menor número de municípios, potencial de arrecadação própria dos municípios e distribuição demográfica. É possível expandir os resultados desta pesquisa para outras receitas de transferências intergovernamentais que utilizam como critério distributivo o valor per capita, nestas inserem-se às transferências do Sistema Único de Saúde - SUS.

\section{Referências}

ARELARO, Lisete; GIL, Juca. Política de fundos na educação: duas posições. In: LIMA, Maria José Rocha; VITAL, Didonet. Fundeb Fundo de Manutenção e Desenvolvimento da Educação Básica e de Valorização dos Profissionais da Educação: avanços na universalização da educação básica. Brasília: INEP, 2006.

BRASIL. Constituição da República Federativa do Brasil. Diário Oficial da União, Brasília, 5 de outubro de 1988.

BRASIL. Lei $n^{\circ}$ 11.494. Regulamenta o Fundo de Manutenção e Desenvolvimento da Educação Básica e de Valorização dos Profissionais da Educação... Diário Oficial da União, Brasília, 2007. 
A Política de Fundos (Fundef/Fundeb) e suas Disparidades no Financiamento da Educação Básica no Estado do Rio Grande do Sul

BRASIL. Fundo Nacional de Desenvolvimento da educação (FNDE). Resolução $n^{0} 1$, de 29 de julho de 2015. Aprova as ponderações aplicáveis entre diferentes etapas, modalidades e tipos de estabelecimento de ensino da educação básica, para vigência no exercício de 2016. Diário Oficial da União, Brasília, 2015.

BREMAEKER, François Eugene Jean de. A Política de Fundos para a Educação e o Impacto nas Finanças dos Estados e dos Municípios. In: GOUVEIA, Andréa Barbosa; PINTO, José Marcelino Rezende; CORBUCCI, Paulo Roberto (Org.). Federalismo e Políticas Educacionais na Efetivação do Direito à Educação no Brasil. Brasília: Ipea, 2011.

CASTRO, Jorge Abrahão de. Financiamento da Educação Pública no Brasil: evolução dos gastos. In: GOUVEIA, Andréa Barbosa; PINTO, José Marcelino Rezende; CORBUCCI, Paulo Roberto (Org.). Federalismo e Políticas Educacionais na Efetivação do Direito à Educação no Brasil. Brasília: Ipea, 2011.

COUTO, Maria. A Descentralização da Gestão da Educação e a Municipalização do Ensino como Temas de Estudos Recentemente Produzidos no Brasil. Brasília: Anped, 2006. Disponível em: <http://www.anped.org.br/reunioes/29ra/trabalhos/trabalho/GT05-2059-Int.pdf>. Acesso em: 4 jun. 2012.

CRUZ, Rosana Evangelista da. Pacto Federativo e Financiamento da Educação: a função supletiva e redistributiva da União - O FNDE em destaque. 2009. Tese (Doutorado em Educação) - Programa de Pós-Graduação em Educação da Faculdade de Educação, Universidade de São Paulo, São Paulo, 2009.

CRUZ, Rosana Evangelista da. Federalismo e Financiamento da Educação: a política do FNDE em debate. In: GOUVEIA, Andréa Barbosa; PINTO, José Marcelino Rezende; CORBUCCI, Paulo Roberto (Org.). Federalismo e Políticas Educacionais na Efetivação do Direito à Educação no Brasil. Brasília: Ipea, 2011.

FUJITA, Masahisa; KRUGMAN, Paul; VENABLES, Anthony. Economia Espacial: urbanização, prosperidade econômica e desenvolvimento humano no mundo. São Paulo: Futura, 2002.

MENDES, Constantino Cronenberger. Padrões Regionais da Despesa Pública Municipal no Brasil. Rio de Janeiro: Ipea, 2012.

MENDES, Marcos; MIRANDA, Rogério Boueri; COSIO, Fernando Blanco. Transferências Intergovernamentais no Brasil: diagnóstico e proposta de reforma. Brasília: Senado Federal, 2008.

MYRDAL, Gunnar. Teoria Econômica e Regiões Subdesenvolvidas. Rio de Janeiro: Saga, 1965.

PINTO, José Marcelino de Rezende. A Política Recente de Fundos para o Financiamento da Educação e seus Efeitos no Pacto Federativo. Educação e Sociedade, Campinas, v. 28, n. 100, p. 877-897, 2007.

VERHINE, Robert. Determinação de Custos Educacionais: uma análise panorâmica do estado da arte. Educação, Porto Alegre, v. 21, n. 35, p. 107-122, 1998. 
A Política de Fundos (Fundef/Fundeb) e suas Disparidades no Financiamento da Educação Básica no Estado do Rio Grande do Sul

Nelton Carlos Conte é doutor em Desenvolvimento Regional (UNISC (2017). Atualmente é professor Adjunto da Universidade de Passo Fundo. Tem experiência na área de Ciências Contábeis e Administração Pública, atuando principalmente nos seguintes temas: Administração Pública; Finanças Pública; Contabilidade Pública; Federalismo Fiscal e Tributação.

E-mail: conte@upf.br 


\title{
Editores do volume 8
}

José Marcelino de Rezende Pinto - Universidade de São Paulo, São Paulo/SP, Brasil

Nalú Farenzena - Universidade Federal do Rio Grande do Sul, Porto Alegre/RS, Brasil

\section{Comitê Editorial}

José Marcelino de Rezende Pinto - Universidade de São Paulo, Brasil

Juca Gil - Universidade Federal do Rio Grande do Sul, Brasil

Theresa Adrião - Universidade Estadual de Campinas, Brasil Ângelo

Ricardo de Souza - Universidade Federal do Paraná, Brasil

Márcia Aparecida Jacomini - Universidade Federal de São Paulo, Brasil

\section{Conselho Editorial}

\section{Alejandro Morduchowicz}

Universidad Pedagógica, Provincia de Buenos Aires, Argentina

Fernanda Saforcada

Universidade de Buenos Aires, Argentina

Jacques Velloso

Universidade de Brasília, Brasil

João Monlevade

Senado Federal, Brasil

Jorge Abrahão de Castro

Instituto de Pesquisa Econômica Aplicada / IPEA, Brasil

Juca Gil

Universidade Federal do Rio Grande do Sul, Brasil

Lisete Regina Gomes Arelaro

Universidade de São Paulo, Brasil

Luis Carlos Sales

Universidade Federal do Piauí, Brasil

Luiz de Sousa Junior

Universidade Federal da Paraíba, Brasil

Luiz Fernandes Dourado

Universidade Federal de Goiás, Brasil

Magna França

Universidade Federal do Rio Grande do Norte, Brasil

\section{Maria Beatriz Luce}

Universidade Federal do Pampa, Brasil

Universidade Federal do Rio Grande do Sul, Brasil

Marcos Edgar Bassi

Universidade Federal do Paraná, Brasil

\author{
Maria Dilnéia Espíndola Fernandes \\ Universidade Federal de Mato Grosso do Sul, Brasil \\ Nalú Farenzena \\ Universidade Federal do Rio Grande do Sul, Brasil \\ Nelson Cardoso do Amaral \\ Universidade Federal de Goiás, Brasil \\ Nicholas Davies \\ Universidade Federal Fluminense, Brasil \\ Rosana Evangelista Cruz \\ Universidade Federal do Piauí, Brasil \\ Rosana Gemaque \\ Universidade Federal do Pará, Brasil \\ Robert E. Verhine \\ Universidade Federal da Bahia, Brasil \\ Romualdo Portela de Oliveira \\ Universidade de São Paulo, Brasil \\ Theresa Adrião \\ Universidade Estadual de Campinas, Brasil \\ Tristan McCowan \\ University of London, Reino Unido \\ Vera Jacob \\ Universidade Federal do Pará, Brasil \\ Vera Peroni \\ Universidade Federal do Rio Grande do Sul, Brasil \\ Vitor Henrique Paro \\ Universidade de São Paulo, Brasil
}

\section{Equipe editorial}

Apoio ao Comitê Editorial: Patrícia Balthazar Garcia

Diagramação, Revisão de português e normalização: Edson Leonel de Oliveira

Revisão de inglês: Ananyr Porto Fajardo 